\title{
Actinomycosis in the Mandible: CT and MR Findings
}

\author{
Y. Sasaki, T. Kaneda, J.W. Uyeda, H. Okada, K. Sekiya, M. Suemitsu, and O. Sakai
}

\begin{abstract}
SUMMARY: Mandibular actinomycosis is an uncommon disease. We retrospectively reviewed 6 patients with pathologically proven mandibular actinomycosis who underwent both CT and MR imaging to evaluate the characteristic imaging findings. CT results showed an irregularly marginated lesion with increased bone marrow attenuation, osteolysis, and involvement of the skin in all patients. Periosteal reaction and intralesional gas were seen in 4 patients. MR imaging results revealed low signal on T1-weighted and high signal on T2-weighted images of the mandible, and moderate heterogeneous enhancement was seen in all patients who received intravenous contrast. Cervical lymphadenopathy was not observed. Involvement of the masseter, lateral pterygoid, and medial pterygoid muscles was seen in 4 patients, whereas parotid gland and submandibular gland as well as parapharyngeal space involvement were seen in 3 patients. Familiarity with the imaging findings of mandibular actinomycosis may help to diagnosis this entity.
\end{abstract}

ABBREVIATION: $M A=$ mandibular actinomycosis

M andibular actinomycosis (MA) is an uncommon disease caused by Actinomyces israelii. ${ }^{1}$ Actinomycosis infection typically manifests as a chronic disease resulting in multiple abscesses, firm soft tissue masses, and the presence of sulfur granules in exudates or tissues. ${ }^{2}$ When the infection involves bone, osteolysis is likely to occur. ${ }^{3}$ In the maxillofacial region, infection is frequently of odontogenic origin, the result of oromaxillofacial trauma, dental manipulation, or dental caries. ${ }^{1-10}$

Intraoral and panoramic radiographs are often used to assess various diseases and conditions of the maxilla and mandible in the dental clinic, ${ }^{3}$ but the imaging findings are often nonspecific, and differentiating actinomycosis from other inflammatory or infectious conditions or from neoplastic processes is difficult and often necessitates additional imaging. ${ }^{2,4}$ A few reports have described imaging findings of actinomycosis in the head and neck, ${ }^{2-4,6,8,11}$ but the CT and MR imaging characteristics of MA have not been fully described. The purpose of this study was to evaluate the characteristic CT and MR imaging findings of MA.

Received March 25, 2013; accepted after revision April 13.

From the Departments of Radiology (Y.S., T.K., K.S.), Histology (H.O.), and Pathology (M.S.), Nihon University School of Dentistry at Matsudo, Chiba, Japan; and Department of Radiology (J.W.U., O.S.) Boston Medical Center, Boston University School of Medicine, Boston, Massachusetts.

Paper previously presented at: Annual Meeting of the American Society of Neuroradiology; April 21-26, 2012, New York, New York.

Please send correspondence to Yusuke Sasaki, DDS, PhD, Department of Radiology, Nihon University School of Dentistry at Matsudo, 2-870-1, Sakaecho-Nishi, Matsudo, Chiba 271-8587, Japan; e-mail: sasaki.yusuke@nihon-u.ac.jp

http://dx.doi.org/10.3174/ajnr.A3673

\section{CASE SERIES \\ Patients}

After institutional review board approval, a retrospective review of our imaging data base was performed to identify patients with pathologically proven MA between April 2006 and November 2008. Both the dental history and the chief presenting complaint were evaluated, and the preoperative initial imaging diagnosis was reviewed. Histologic diagnosis was established after surgical excision in all patients.

\section{Imaging Analysis}

CT studies were performed with a 64-row multidetector CT scanner (Aquilion 64; Toshiba Medical Systems, Tokyo, Japan) with the following parameters: reconstruction thickness, $0.5 \mathrm{~mm}$; tube voltage, $120 \mathrm{kV}$; tube current, $100 \mathrm{~mA}$; and field of view, $240 \mathrm{~mm} \times 240 \mathrm{~mm}$. In all cases, multiplanar reformations in the coronal and sagittal planes were provided $(1.0 \mathrm{~mm} \times 3.0 \mathrm{~mm})$. All images were reconstructed by use of bone and soft tissue algorithms and evaluated in bone and soft tissue windows, respectively (bone window, level: 500, width: 2800; soft tissue window, level: 30, width: 300). MR imaging was performed by use of a 1.5T MR scanner (Intera Achieva 1.5T; Philips Healthcare, Best, the Netherlands) with a head coil. Axial and coronal spin-echo T1-weighted images (TR, 500-600 ms; TE, 9.0 $\mathrm{ms}$; section thickness, $6 \mathrm{~mm}$ ), turbo spin-echo T2-weighted images (TR, 6000-8000 ms; TE, $130 \mathrm{~ms}$; section thickness, $6 \mathrm{~mm}$ ), and STIR (TR, $2500 \mathrm{~ms}$; TE, $50 \mathrm{~ms}$; TI, $180 \mathrm{~ms}$; and section thickness, $6 \mathrm{~mm}$ ) images were obtained in all patients. Contrast was administered in 1 

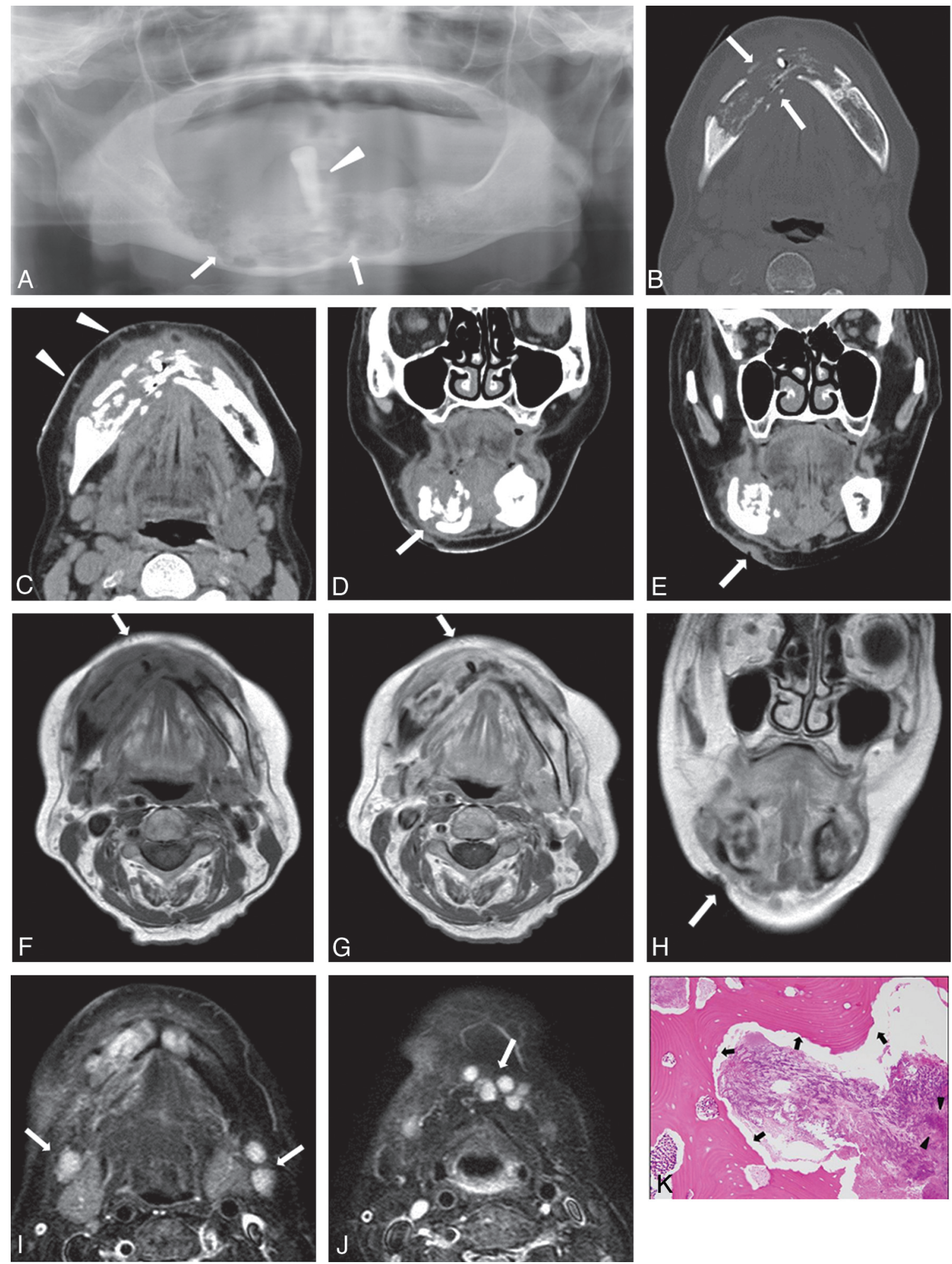

FIG 1. A 68-year-old woman with discharge of pus on the right side of the face. A, Panoramic radiograph reveals a large osteolytic region (arrows), with a floating tooth (arrowhead), in the right mandibular body crossing the midline. Axial CT in bone (B) and soft tissue (C) windows reveals an ill-defined osteolytic lesion in the right mandibular body crossing the midline (arrows). Note extensive demineralization of the buccal and lingual cortices and extensive soft tissue infiltrative change extending to the skin (arrowheads). D and E, Coronal CT in soft tissue window shows bone destruction and fistula from the mandible to the skin (arrows). F, Axial T1-weighted MR image shows heterogeneous, low signal intensity in the lesion involving the mandible and surrounding soft tissues (arrow). G, Contrast-enhanced axial T1-weighted MR image shows heterogeneous mass with moderate contrast enhancement in the lesion involving the mandible and surrounding soft tissues (arrow). $H$, Coronal T2-weighted MR image shows a fistula (arrow). I and J, Axial STIR MR images shows multiple mildly reactive nodes with increased signal intensity in levels IA and IB (arrows). K, Photomicrograph of a specimen shows actinomycotic granules (arrowheads) and presence of sequestra (arrows) (hematoxylin-eosin stain, original magnification $\times 200$ ). 

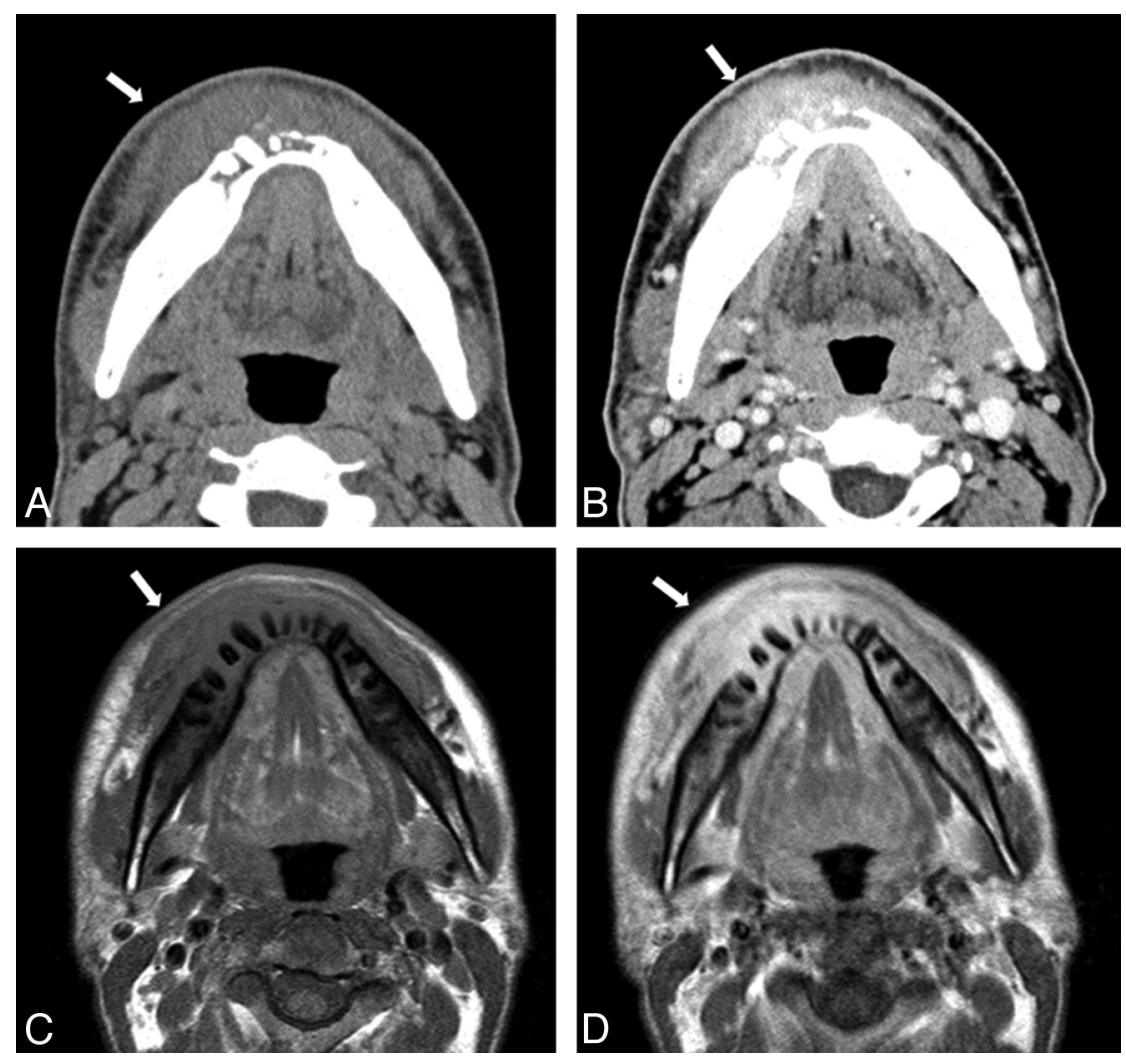

FIG 2. A 40-year-old man with discharge of pus on the right side of the face. A, Axial CT in soft tissue window reveals extensive soft tissue (outer layer fat around mandible) infiltrative change extending to the skin (arrow). B, Contrast-enhanced axial CT scan in soft tissue window reveals a heterogeneous, moderately enhancing mass in the lesion and extensive soft tissue (outer layer fat around mandible) infiltrative change extending to the skin (arrow). Axial T1-weighted (C) and contrast-enhanced axial T1-weighted $(D)$ MR imaging reveals heterogeneous, low signal intensity in the lesion involving the mandible and surrounding soft tissues (arrow). Note this lesion shows diffuse and moderate contrast enhancement of the soft tissue and marrow space.
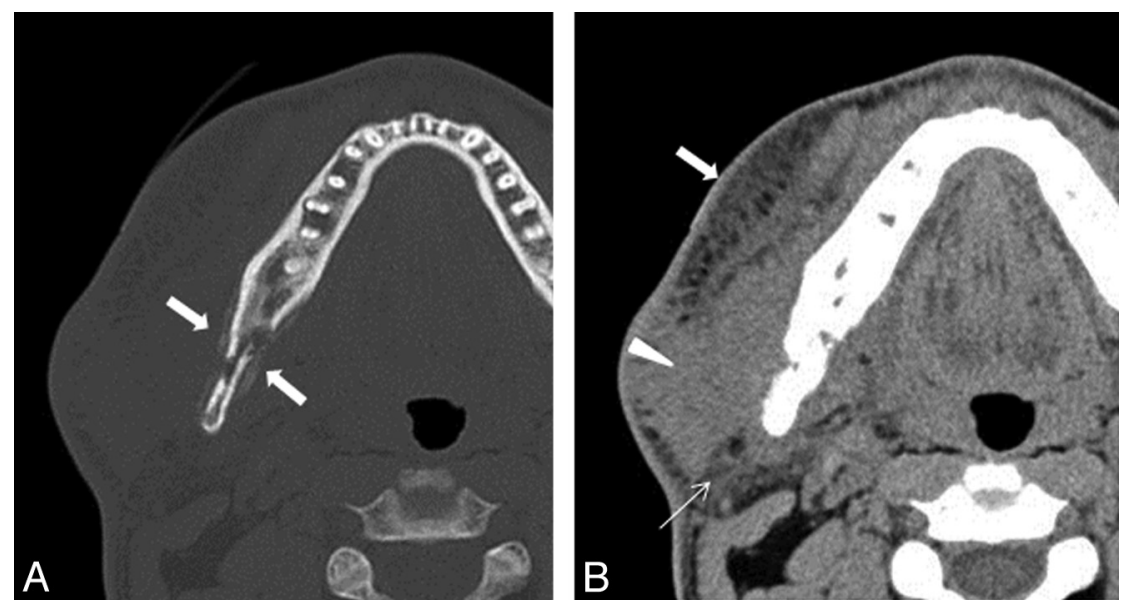

FIG 3. A 28-year-old man with swelling of the right mandibular region. A, Axial CT in bone window shows a heterogeneous osteolytic lesion with periosteal reaction in the posterior body to ramus of the right mandible (arrows). B, Axial CT in soft tissue window shows extensive soft tissue infiltrative change extending to the skin (arrow), masseter muscle (arrowhead), and parotid gland (thin arrow).

margin, attenuation or signal intensity of the lesions, associated osteolysis or sclerosis, periosteal reaction, intralesional gas, fistula formation, enhancement pattern of the lesions, and presence of cervical lymphadenopathy in levels I and II were recorded. The margins of the lesions were classified as either well- or ill-defined. Lymphadenopathy was defined as a lymph node $>10 \mathrm{~mm}$ in the short axis or by the presence of an intranodal abscess. A lymph node measuring $<10 \mathrm{~mm}$ in the short axis with increased signal intensity on STIR images but without intranodal abscess was considered to be a reactive node.

\section{Imaging Findings}

Review of our imaging data base revealed 6 patients with pathologically proven MA ( 3 men and 3 women; mean age, 51 years; age range, $28-68$ years). A history of extraction of the third molar was seen in 3 patients. On physical examination, all patients had pain and swelling of the affected areas suggestive of chronic inflammation or infection, but a neoplastic process could not be completely excluded. Therefore, these patients underwent CT and MR imaging studies. Some patients had multiple findings involving muscles and/or parotid and submandibular glands. The number of various organs involved is more than the number of patients.

All 6 patients underwent unenhanced CT scanning, and 1 of 6 patients subsequently received an additional contrast-enhanced CT scan. The lesions demonstrated irregular margins with soft tissue inflammatory changes, which extended to the surface of the skin in all cases (Figs 1 and 2), and a soft tissue fistula was seen in 4 patients (Fig 1). Periosteal reaction was observed in 4 patients (Fig 3). Moderate heterogeneous contrast enhancement was seen in a patient who received intravenous contrast administration (Fig 2). Intralesional gas was seen in 4 patients (Fig 4) (Table 1).

On MR imaging scans, the lesions demonstrated signal intensity similar to muscle on T1-weighted images (Figs 1

patient who underwent CT scanning and 2 patients who underwent MR imaging. Two radiologists (Y.S. and T.K.) independently reviewed the CT and MR images, and any discrepancy was solved by consensus of the 2 radiologists. The location, extension, and 2), and intermediate to high signal intensity on T2-weighted images. Heterogeneous, moderate enhancement was seen within the lesions, bone marrow, and affected soft tissues in 2 patients who received intravenous contrast (Figs 1 and 3). Ad- 
jacent soft tissue involvement was seen in all patients on MR imaging. Involvement with inflammatory change of the masseter muscle was seen in 4 patients. Four patients had involvement of the masseter, lateral pterygoid, and medial pterygoid muscles (Fig 4). Three patients had involvement of the parotid and submandibular glands. The parapharyngeal space was affected in 3 patients (Figs 1 and 2) (Table 2).

Pathologic cervical lymphadenopathy was not seen in any patients, but reactive-appearing nodes were visualized in levels I and II in all patients (Fig 1).

\section{DISCUSSION}

Actinomycosis is an unusual chronic suppurative bacterial infection usually caused by $A$ israelii that most often affects the cervicofacial region, accounting for approximately $50 \%$ of all patients. ${ }^{5}$ Most reports note a predilection for male patients with a male-to-female ratio of $3: 1-4: 1 .^{11}$
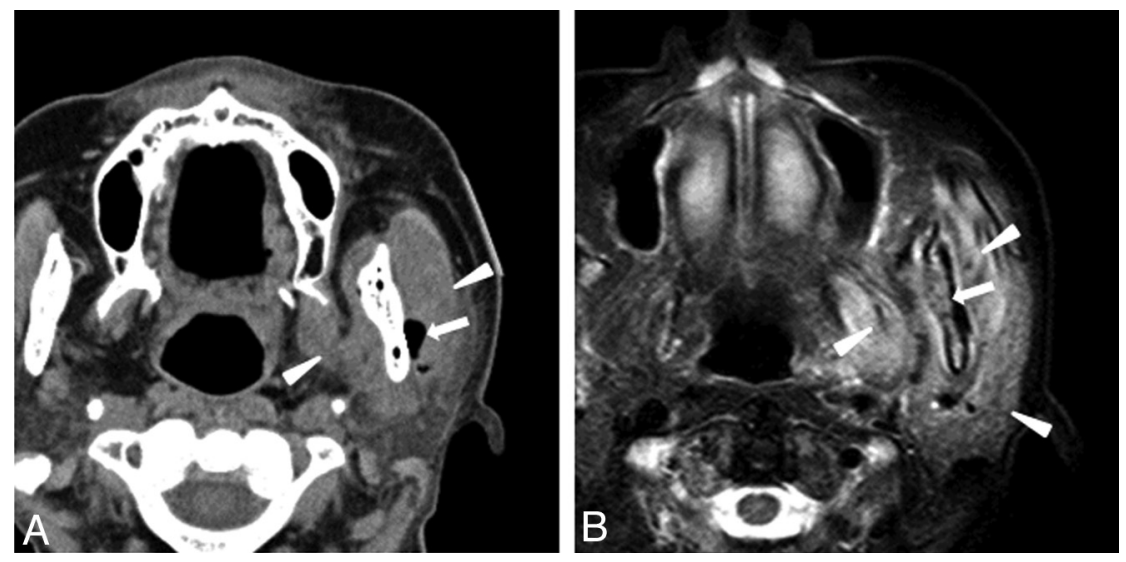

FIG 4. A 66-year-old woman with swelling of left mandibular region. A, Axial CT in soft tissue window demonstrates foci of air adjacent to the left mandible (arrow) and swelling of masseter and medial pterygoid muscle (arrowheads). B, Axial STIR MR image shows extensive inflammation in the left masseter muscle, medial pterygoid muscles, parotid gland (arrowheads), and mandibular bone marrow (arrow).
The clinical diagnosis of actinomycosis is difficult, as it may mimic a neoplasm. ${ }^{2,4}$ The most common clinical finding of actinomycosis is a firm palpable mass with a subacute clinical course. ${ }^{4}$ Approximately half of patients present with a low-grade fever. ${ }^{7}$ Because actinomycosis species are anaerobic bacteria that cannot penetrate healthy tissue, mucosal breakdown is a prerequisite for infection. ${ }^{5}$ Roughly half of patients have a history of local trauma resulting in mucosal breakdown, with poor dental hygiene, caries, oral trauma, dental extraction, and an immunocompromised status being important predisposing factors. ${ }^{5}$ A presumptive diagnosis of actinomycosis can be made by identification of sulfur granules in an abscess or in the secretions from a sinus tract, ${ }^{6}$ but only $10 \%$ of actinomycotic infections are correctly diagnosed at the time of initial presentation. ${ }^{7}$ The diagnosis of actinomycosis is made most accurately by isolation of Actinomyces species in cultures of clinical specimens. ${ }^{6}$ The visualization of actinomycotic granules in exudates or in histopathologic tissue sections is strongly supportive of the diagnosis. ${ }^{7}$

In the literature, an enhancing soft tissue mass with invasion in the cervicofacial region and rarefying osteomyelitis in MA have been described. ${ }^{2}$ In our study, all lesions had ill-defined, infiltrative margins with surrounding soft tissue inflammatory response that extended to the skin. Soft tissue fistula/ sinus tract formation and intralesional gas were seen in 4 of 6 patients; these findings are useful to differentiate actinomycosis from other infection. Osteomyelitis caused by actinomycosis demonstrates intralesional gas from anaerobic breakdown or fistulas within the mouth, whereas mandibular osteomyelitis caused by other organisms does not typically result in fistulas or intral-

Table 1: CT imaging features of MA

\begin{tabular}{|c|c|c|c|c|c|c|c|c|c|}
\hline \multirow[b]{2}{*}{$\begin{array}{l}\text { Patient No/ } \\
\text { Age (y)/Sex }\end{array}$} & \multicolumn{9}{|c|}{ СT Imaging Findings } \\
\hline & $\begin{array}{c}\text { Contrast } \\
\text { Enhancement }\end{array}$ & Margin & Density & $\begin{array}{c}\text { Intralesional } \\
\text { Gas }\end{array}$ & Fistula & Osteolysis & $\begin{array}{c}\text { Periosteal } \\
\text { Reaction }\end{array}$ & Sequestra & Lymphadenopathy \\
\hline $1 / 40 / M$ & Mod. heterog. & Irregular & Low-intermed. & - & + & + & + & + & - \\
\hline $2 / 34 / \mathrm{M}$ & Not done & Irregular & Low-intermed. & + & + & + & - & - & - \\
\hline $3 / 66 / F$ & Not done & Irregular & Low-intermed. & + & - & + & + & + & - \\
\hline $4 / 28 / M$ & Not done & Irregular & Low-intermed. & - & + & + & + & + & - \\
\hline $5 / 78 / F$ & Not done & Irregular & Low-intermed. & + & + & + & + & + & - \\
\hline $6 / 68 / F$ & Not done & Irregular & Low-intermed. & + & - & + & - & - & - \\
\hline
\end{tabular}

Note:-F indicates female; M, male; Low-intermed., low to intermediate; Mod. heterog., moderate heterogeneous.

Table 2: MR imaging features of actinomycosis in the mandible

\begin{tabular}{|c|c|c|c|c|c|}
\hline \multirow[b]{2}{*}{ Patient No } & \multicolumn{5}{|c|}{ MRI Findings } \\
\hline & $\begin{array}{c}\text { Gadolinium } \\
\text { Enhancement }\end{array}$ & $\begin{array}{l}\text { Cellulitis Adjacent } \\
\text { to the Facial Skin }\end{array}$ & $\begin{array}{l}\text { Inflammation of } \\
\text { Masseter Muscle }\end{array}$ & $\begin{array}{l}\text { Inflammation of } \\
\text { Pterygoid Muscle }\end{array}$ & $\begin{array}{l}\text { Lymph } \\
\text { Adenopathy }\end{array}$ \\
\hline 1 & Moderate heterogeneous & + & - & - & \\
\hline 2 & Not done & + & + & - & - \\
\hline 3 & Not done & + & + & + & - \\
\hline 4 & Not done & + & + & + & - \\
\hline 5 & Not done & + & + & + & - \\
\hline 6 & Moderate heterogeneous & + & + & + & - \\
\hline
\end{tabular}

Note:-+ indicates findings present; - , findings absent. 
esional gas. ${ }^{12}$ MR imaging has higher accuracy in the detection of inflammatory and infiltrative changes in the surrounding soft tissue extending to the skin, ${ }^{13}$ particularly in the muscles of mastication, though visualization of gas is challenging. Although bone marrow signal changes of MA were similar to osteomyelitis secondary to other causes, ${ }^{13}$ very extensive soft tissue inflammatory and infiltrative changes in the surrounding soft tissues extending to the skin may be useful in the differentiation of actinomycosis from osteomyelitis due to other causes. In particular, extensive soft tissue inflammation extending to the skin surface and forming fistulas appeared to be characteristic for actinomycosis.

Lymphadenopathy is thought be a relatively uncommon finding in actinomycosis because the organism does not spread via the lymphatic system secondary to the size of the bacterium. ${ }^{1,2}$ None of our patients showed lymphadenopathy measuring more than $10 \mathrm{~mm}$ in the short axis, though mildly reactive nodes with increased signal intensity on STIR images but without intranodal abscess were seen in all patients. An et $\mathrm{al}^{14}$ reported that cervical lymphadenopathy was present in approximately $40 \%$ of mandibular osteomyelitis cases from ordinal bacterial infection. Therefore, absence of lymphadenopathy may be suggestive of MA rather than other acute or chronic infections or malignant tumors, particularly in patients with extensive soft tissue changes with fistula formation.

\section{CONCLUSIONS}

CT and MR imaging findings of MA were reviewed. Characteristics imaging findings including the presence of intralesional gas, osteolytic changes with extensive inflammatory changes in the surrounding soft tissue extending to the skin surface, fistula formation, and absence of lymphadenopathy were frequently seen and are helpful in narrowing the differential diagnosis.

Disclosures: Osamu Sakai-UNRELATED: Royalties: Sakai O. Head and neck imaging cases. McGraw-Hill Companies.

\section{REFERENCES}

1. Hansen T, Kunkel M, Springer E, et al. Actinomycosis of the jawshistopathological study of $\mathbf{4 5}$ patients shows significant involvement in bisphosphonate-associated osteonecrosis and infected osteoradionecrosis. Virchows Arch 2007;451:1009-17

2. Park JK, Lee HK, Ha HK, et al. Cervicofacial actinomycosis: CT and MR imaging findings in seven patients. AJNR Am J Neuroradiol 2003;24:331-35

3. Smith MH, Harms PW, Newton DW, et al. Mandibular actinomyces osteomyelitis complicating florid cemento-osseous dysplasia: case report. BMC Oral Health 2011;11:21

4. Sa'do B, Yoshiura K, Yuasa K, et al. Multimodality imaging of cervicofacial actinomycosis. Oral Surg Oral Med Oral Pathol 1993;76:772-82

5. Belmont MJ, Behar PM, Wax MK. Atypical presentations of actinomycosis. Head Neck 1999;21:264-68

6. Nagler R, Peled, Laufer D. Cervicofacial actinomycosis: a diagnostic challenge. Oral Surg Oral Med Oral Pathol Oral Radiol Endod 1997;83:652-56

7. Oostman $\mathrm{O}$, Smego RA. Cervicofacial actinomycosis: diagnosis and management. Curr Infect Dis Rep 2005;7:170-74

8. Kemp FH, Vollum L. Anaerobic cellulitis due to actinomyces, associated with gas production. Br J Radiol 1946;19:248

9. Nielsen PM, Novak A. Acute cervico-facial actinomycosis. Int J Oral Maxillofac Surg 1987;16:440-44

10. Bennhoff DF. Actinomycosis: diagnostic and therapeutic considerations and a review of 32 cases. Laryngoscope 1984;94: $1198-217$

11. Miller M, Haddad AJ. Cervicofacial actinomycosis. Oral Surg Oral Med Oral Pathol Oral Radiol Endod 1998;85:496-508

12. Adekeye EO, Cornah J. Osteomyelitis of the jaws: a review of $\mathbf{1 4 1}$ cases. Br J Oral Maxillofac Surg 1985;23:24-35

13. Lee K, Kaneda T, Mori S, et al. Magnetic resonance imaging of normal and osteomyelitis in the mandible: assessment of short inversion time inversion recovery sequence. Oral Surg Oral Med Oral Pathol Oral Radiol Endod 2003;96:499-507

14. An CH, An SY, Choi BR, et al. Hard and soft tissue changes of osteomyelitis of the jaws on CT images. Oral Surg Oral Med Oral Pathol Oral Radiol 2012;114:118-26 